\title{
A comprehensive investigation on afternoon transition of the atmospheric boundary layer over a tropical rural site
}

\author{
A. Sandeep ${ }^{1}$, T. N. Rao ${ }^{1}$, and S. V. B. Rao ${ }^{2}$ \\ ${ }^{1}$ National Atmospheric Research Laboratory, Gadanki - 517 112, India \\ ${ }^{2}$ Sri Venkateswara University, Department of Physics, Tirupati - 517 502, India \\ Correspondence to: T. N. Rao (tnrao@narl.gov.in, drtnr2001@yahoo.com)
}

Received: 30 October 2014 - Published in Atmos. Chem. Phys. Discuss.: 12 December 2014

Revised: 17 June 2015 - Accepted: 25 June 2015 - Published: 14 July 2015

\begin{abstract}
The transitory nature of the atmospheric boundary layer (ABL) a few hours before and after the time of sunset has been studied comprehensively over a tropical station, Gadanki $\left(13.45^{\circ} \mathrm{N}, 79.18^{\circ} \mathrm{E}\right)$, using a suite of in situ and remote sensing devices. This study addresses the following fundamental and important issues related to the afternoon transition (AT): which state variable first identifies the AT? Which variable best identifies the AT? Does the start time of the AT vary with season and height? If so, which physical mechanism is responsible for the observed height variation in the start time of the transition?

At the surface, the transition is first seen in temperature $(T)$ and wind variance $\left(\sigma_{\mathrm{WS}}^{2}\right), \sim 100 \mathrm{~min}$ prior to the time of local sunset, then in the vertical temperature gradient and finally in water vapor mixing ratio variations. Aloft, both signal-to-noise ratio (SNR) and spectral width $(\sigma)$ show the AT nearly at the same time. The $T$ at the surface and SNR aloft are found to be the best indicators of transition. Their distributions for the start time of the AT with reference to time of sunset are narrow and consistent in both total and seasonal plots. The start time of the transition shows some seasonal variation, with delayed transitions occurring mostly in the rainy and humid season of the northeast monsoon. Interestingly, in contrast to the general perception, the signature of the transition is first seen in the profiler data, then in the sodar data, and finally in the surface data. This suggests that the transition follows a top-to-bottom evolution. It indicates that other processes, like entrainment, could also play a role in altering the structure of the ABL during the AT, when the sensible heat flux decreases progressively. These mechanisms are quantified using a unique high-resolution data set
\end{abstract}

to understand their variation in light of the intriguing height dependency of the start time of the AT.

\section{Introduction}

The behavior of the atmospheric boundary layer (ABL) during the transition from a well-mixed layer during the day to a stably stratified layer during the night is quite complex and is also poorly understood. In recent years, the afternoon transition (AT) and evening transition (ET) of the ABL have gained attention for various reasons (Lothon et al., 2014). These transitional regimes are found to be important for the vertical transport of species, like pollutants, water vapor and ozone (Klein et al., 2014), the inception and strength of the nocturnal low-level jet (LLJ) (Mahrt, 1981; Van De Wiel et al., 2010), and the whole structure of the nocturnal boundary layer. Furthermore, identification of the ABL becomes uncertain and there is no consensus on which scaling laws (day-time convective scaling due to surface buoyancy flux or nocturnal boundary layer scaling due to surface wind stress) would work well during this period (Pino et al., 2006). Furthermore, the start time of the transition and its duration could be different at the surface and aloft because the turbulence may not immediately dissipate after the sunset (Busse and Knupp, 2012).

Researchers defined the transition in a variety of ways employing various parameters obtained from different instruments. Some of them treated the transition as an instantaneous process, while the others considered it as a process of a few hours. The most popular and widely used definition is the reversal of surface heat flux (positive to negative) 
(Grant, 1997; Acevedo and Fitzjarrald, 2001; Beare et al., 2006; Angevine, 2008). A similar technique is employed by Nieuwstadt and Brost (1986), in which the AT is assumed to occur following the cessation of upward surface sensible heat flux. Edwards et al. (2006) noted that the shortwave heating starts to decrease long before the surface heat flux changes its sign. They included the shortwave heating in the definition of the AT, which shifted the start of the afternoon transition to an earlier time. Acevedo and Fitzjarrald (2001) identified the start time of the transition from a sharp decrease in the spatial temperature difference and end from the maximum spatial standard deviation of temperature. As seen above, all these definitions are based on surface measurements and do not account for the physical processes occurring aloft during the transition.

The studies that used remote sensing measurements like wind profiling radars, sodars and lidars focused more on the processes aloft (mostly in the lower part of ABL) to define the AT. In a seminal study, Mahrt (1981) used a kinematic definition for the AT period. According to Mahrt (1981), the AT is a 4-5 h time period, starts from the time of low-level wind deceleration (typically $2 \mathrm{~h}$ before the sunset) and ends when the flow at all levels turned towards the high pressure. Grimsdell and Angevine (2002) and Angevine (2008), using radar wind profiler measurements, noticed that both reflectivity (range-corrected signal-to-noise ratio (SNR)) and the spectral width $(\sigma)$ (a measure of turbulence) decrease sharply during the AT. The applicability of these approaches is always an issue, particularly when the turbulence is either weak or strong throughout the day or when the turbulence increases due to some other processes associated with katabatic winds or land sea-breeze circulations (Sastre et al., 2012). Instead of defining the start and end times for the AT, Busse and Knupp (2012) studied the variations in meteorological parameters with reference to the sunset time. They noted an increase in wind speed and a decrease in sodar return power in the lower ABL. They found that the AT has a relatively consistent pattern regardless of season.

A few studies employed models to understand or validate the occurrence of different types of transition (Brazel et al., 2005; Edwards et al., 2006; Pino et al., 2006; Sorbjan, 2007; Nadeau et al., 2011; Sastre et al., 2012). Brazel et al. (2005) studied the evening transition under weak synoptic forcing that favors the local thermal circulations and compared the observed transitions with models. Recently, Sastre et al. (2012) identified three types of evening transitions and evaluated the performance of the Weather Research and Forecasting Advanced Research (WRF-ARW) model in reproducing these transitions by varying PBL parameterization schemes. They noted that all parameterizations reproduced the observed behavior of AT in certain circumstances. Noting the need to understand the transitions in a better way, several field campaigns were conducted in recent years, employing both in situ and remote sensors, exclusively for better characterization and modeling of the tran- sitions, for instance, the Cooperative Atmosphere-Surface Exchange Study (CASES-99) (Poulos et al., 2002), Boundary Layer Late Afternoon and Sunset Turbulence (BLLAST) (http://bllast.sedoo.fr/) (Lothon et al., 2014) and the Phoenix Evening Transition Flow Experiment (TRANSFLEX) (Fernando et al., 2013). Recently, manned and unmanned aerial vehicles were used to study the vertical structure of the lowest part of the ABL during the AT (Bonin et al., 2013; Lothon et al., 2014).

Most of the above studies focused on the variations in state variables like temperature, humidity, wind and turbulence in the surface layer, as they are easily accessible. Other studies characterized the evening transitions aloft, but neglected the variations at the surface. Only a few studies that were based on campaign data and/or a few months of data dealt with the transitions in totality, i.e., studied the variations at the surface and aloft (Busse and Knupp, 2012; Fernando et al., 2013; Lothon et al., 2014). Again, the data employed in those studies were limited: a few days to 2 months. Certainly there is a need to characterize and understand the transitions at the surface and aloft in different seasons through systematic observations on a long-term basis. Furthermore, earlier studies used different state variables to define the transition. Only a few studies focused on how these state variables vary with reference to the time of sunset (Busse and Knupp, 2012). Although some tower-based observations exist in the literature, the complete understanding of the transition over a deeper layer is certainly far from complete. This forms the basis for the present study. In particular, the study tries to answer the following questions: how do the surface state variables and radar/sodar attributes vary during the transition and with reference to the time of sunset? Which state variable better identifies the transition? How does the start time of the transition vary with height and season? Which physical processes are responsible for the vertical evolution of the transition?

The paper is organized as follows: Sect. 2 introduces the measurement site, data and instrumentation employed. The variation of different state variables at the surface and aloft is studied with the help of a typical case study in Sect. 3. The start time of AT as identified by different state variables and their mean characteristics at the surface and aloft are studied with reference to the time of sunset. The questions posed above are discussed in light of present observations in Sect. 4. The important forcing terms on the ABL are estimated using a unique data set to understand the role of entrainment in the afternoon transition. The important results are concluded in Sect. 5 .

\section{Data and site description}

The present study follows an integrated approach, wherein several instruments available at the National Atmospheric Research Laboratory (NARL), Gadanki $\left(13.45^{\circ} \mathrm{N}\right.$, $79.18^{\circ} \mathrm{E}$ ), are extensively used. This site is located $\sim 375 \mathrm{~m}$ 
above the mean sea level in a rural area in southeastern peninsular India and is surrounded by hillocks (300-800 m within a $10 \mathrm{~km}$ region) distributed in a complex fashion. The rainfall in this region is influenced primarily by two monsoons, southwest (June-September) and northeast (OctoberDecember) (Rao et al., 2009). Summer and winter are the other two seasons, covering the months of March-May and January-February, respectively.

The present study relies on a variety of instruments, both in situ and remote sensors (Table 1), whose measurements cover the entire ABL. Though these instruments provide several other parameters, those used in the present study are only listed in Table 1. Two kinds of data sets (we refer to them here as data set 1 and data set 2) are used in the present study, but for different purposes. Data set 1 was collected with a suite of non-continuously operated instruments, spanning a 3-year period. This data set is being used to examine the seasonality and height dependence of AT. It includes long-term observations made by an instrumented $15 \mathrm{~m}$ tower (hereafter referred to as the Mini Boundary Layer Mast - MBLM), a Doppler sodar and three UHF wind profilers (operated at NARL, but during different years). Data set 2 is comprised of the intense observations, which include the instrumentation of data set 1 along with a flux tower having a sonic anemometer (RM Young 8100) at $8 \mathrm{~m}$ level and radiosondes (Meisei 90) launched every $3 \mathrm{~h}$. Data set 2 was collected over two 3-day campaigns (one during the monsoon and one during the winter). This data set is being used to understand the role of surface forcing and entrainment in triggering the AT.

The MBLM provides temperature $(T)$, relative humidity (RH), wind speed (WS) and wind direction (WD) data at three levels $(5,10$ and $15 \mathrm{~m}$ ) with $1 \mathrm{~s}$ temporal resolution. The type of sensors used and their accuracies are given in Table 2. A Doppler sodar operating at a frequency of $1.8 \mathrm{kHz}$ and a peak power of $100 \mathrm{~W}$ provides the SNR, $\sigma$ and wind information at $27 \mathrm{~s}$ and $30 \mathrm{~m}$ temporal and height resolutions, respectively (Anandan et al., 2008) (see Table 3 for more details about different remote sensing instruments). The UHF wind profiler data consist of the data from three wind profilers, operated during different years. An old UHF wind profiler (referred to as the Lower Atmospheric Wind Profiler LAWP) was operated at a frequency of $1.375 \mathrm{GHz}$ during the period 1999-2000. Complete description of the system and specifications can be found in Reddy et al. (2001) and Rao et al. (2001). It was operated in two modes; low mode covering 0.3 to $4.8 \mathrm{~km}$ and high mode covering 0.9 to $6.8 \mathrm{~km}$, sequentially switching between each mode, providing a temporal resolution of $\sim 11 \mathrm{~min}$. Recently, NARL has indigenously developed two UHF wind profilers with the same frequency $(1.28 \mathrm{GHz})$ but with different antenna dimensions and transmitted powers. The smaller UHF wind profiler that uses an $8 \times 8$ antenna array covering an area of $1.4 \mathrm{~m} \times 1.4 \mathrm{~m}$ transmits a power of $0.8 \mathrm{~kW}$ (hereafter referred to as $\mathrm{WPR}_{8 \times 8}$ ). Whereas, the larger profiler has a bigger antenna array of
$2.8 \mathrm{~m} \times 2.8 \mathrm{~m}$ with $16 \times 16$ elements and high-transmitting power of $1.2 \mathrm{~kW}$ (hereafter referred to as $\mathrm{WPR}_{16 \times 16}$ ). Complete description of these systems and their capabilities can be found in Srinivasulu et al. $(2011,2012)$. The $\mathrm{WPR}_{8 \times 8}$ was operated at NARL during May-September 2010, while the bigger WPR $16 \times 16$ has been in operation from October 2010 . It can be seen from Tables 1 and 3 that these instruments provide a unique long-term data set from the surface to top of the ABL.

A series of automated tests were performed on tower time series data to identify instrumentation problems, flux sampling problems, and physically plausible but unusual situations (Burba, 2013). Furthermore, clear-sky days are identified from shortwave radiation measurements made by a pyranometer (Kipp and Zonen CMP6) located near the MBLM. Omitting the days with large data gaps and rain/dense clouds, 423 days of surface data were available for further analysis from 3 years of MBLM measurements. The range-time plots of spectral moments (SNR, vertical velocity $(w)$ and $\sigma$ ) from sodar and the wind profiler are examined for the clear growth and decay of ABL and convection/precipitation contamination (Grimsdell et al., 2002; Rao et al., 2008). Based on the above criteria, a total of 530 and 482 clear-sky days of sodar and profiler, respectively, were only selected (from data set 1) for further analysis. To examine whether the filtering of data for clear-sky days has caused any bias towards the dry season (winter and summer), the data are segregated on the basis of the season. Table 4 shows the number of days for which the measurements were available, the number of discarded days due to rain, dense cloud or bad data quality and the number of days considered for the present study as a function of the season. Though considerable data were filtered out in the rainy seasons (southwest and northeast monsoons), the number of available days is large enough to represent the season. Also, the number of days available in the rainy season is on the same order as that of other seasons, indicating that the filtering has not biased the results towards any season.

Note that MBLM, sodar and wind profilers were operated during different years. Only 19 days of simultaneous clear-sky measurements (without large data gaps) from all the above sensors were available. Measurements from these 19 days are used to understand the behavior of AT at different altitudes. The total data (from different years, i.e., data set 1) are used to obtain robust statistics on the mean behavior of the AT.

\section{Results and discussion}

\subsection{Typical evolution of the AT from the surface to the top of the ABL}

Figure 1 shows the diurnal variation of surface state variables $(T$, water vapor mixing ratio $(r)$, WS, wind variance $\left(\sigma_{\mathrm{WS}}^{2}\right)$ and wind direction (WD)) and sodar and profiler at- 
Table 1. Instruments used in the integrated approach, their operating frequency, height coverage, vertical and temporal resolutions and duration of data.

\begin{tabular}{|c|c|c|c|c|c|c|}
\hline Instrument & $\begin{array}{l}\text { Frequency } \\
\text { of operation }\end{array}$ & Measured parameters & $\begin{array}{l}\text { Height } \\
\text { coverage }\end{array}$ & $\begin{array}{l}\text { Vertical } \\
\text { resolution }\end{array}$ & $\begin{array}{l}\text { Temporal } \\
\text { resolution }\end{array}$ & Period used \\
\hline SODAR & $1.8 \mathrm{kHz}$ & SNR, winds and $\sigma$ & $0.03-1.5 \mathrm{~km}$ & $30 \mathrm{~m}$ & $27 \mathrm{~s}$ & $2007-2010$ \\
\hline LAWP & $1.357 \mathrm{GHz}$ & SNR, winds and $\sigma$ & $0.3-4.2 \mathrm{~km}$ & $150 \mathrm{~m}$ & $\sim 11 \mathrm{~min}$ & 1999-2000 \\
\hline $\mathrm{WPR}_{8 \times 8}$ & $1.280 \mathrm{GHz}$ & SNR, winds and $\sigma$ & $0.3-6.15 \mathrm{~km}$ & $150 \mathrm{~m}$ & $\sim 10 \mathrm{~min}$ & 2010 \\
\hline $\mathrm{WPR}_{16 \times 16}$ & $1.280 \mathrm{GHz}$ & SNR, winds and $\sigma$ & $0.75-5.025 \mathrm{~km}$ & $75 \mathrm{~m}$ & $\sim 10 \mathrm{~min}$ & $2010-2011$ \\
\hline MBLM & & $\begin{array}{l}T, r, \text { pressure, WS, } \\
\text { WD and shortwave radiation }\end{array}$ & $5-15 \mathrm{~m}$ & $5 \mathrm{~m}$ & $1 \mathrm{~s}$ & 2009-2011 \\
\hline $\begin{array}{l}\text { GPS } \\
\text { Radiosonde }\end{array}$ & & $T, \mathrm{RH}$, pressure & $0-30 \mathrm{~km}$ & $100 \mathrm{~m}$ & $\begin{array}{l}3 \mathrm{~h} \\
21-24 \mathrm{Jul} 2011\end{array}$ & 17-19 Jan 2011 \\
\hline $50 \mathrm{~m}$ tower & & Sonic temperature, vertical wind & $8 \mathrm{~m}$ & & $\begin{array}{l}0.05 \mathrm{~s} \\
21-24 \text { Jul } 2011\end{array}$ & 17-19 Jan 2011 \\
\hline
\end{tabular}

Table 2. Details of measured parameters and sensors (make, model number, resolution and accuracy) on MBLM.

\begin{tabular}{lllcll}
\hline Parameter & Make & Model no. & Resolution & Measurement height & Accuracy \\
\hline Wind speed and wind direction & RM Young & 05103V & $1 \mathrm{~Hz}$ & 5,10 and $15 \mathrm{~m}$ & $0.3 \mathrm{~m} \mathrm{~s}^{-1}{\text { and } 2^{\circ}}^{\circ}$ \\
Temperature and relative humidity & Rotronics & Hygroclip S3 & $1 \mathrm{~Hz}$ & 5,10 and $15 \mathrm{~m}$ & $0.3^{\circ} \mathrm{C}$ and $2 \%$ \\
Pressure & Komoline & KDS-021 & $1 \mathrm{~Hz}$ & $1.2 \mathrm{~m}$ & $1 \mathrm{hPa}$ \\
Shortwave radiation & Kipp \& Zonen & CMP 6 & $1 \mathrm{~Hz}$ & $1.2 \mathrm{~m}$ & $1 \mathrm{~W} \mathrm{~m}^{-2}$ \\
\hline
\end{tabular}

tributes (range-corrected SNR (hereafter referred to simply as SNR), horizontal wind speed, $\sigma, w$ and wind direction) on 11 May 2010, providing a comprehensive paradigm of the typical evolution of the transitional boundary layer at the surface and aloft (up to $3.6 \mathrm{~km}$ ). The surface state variables (at $5 \mathrm{~m}$ level) exhibit larger variations during the transition period than during the rest of the night. During the AT, as the shortwave heating decreases, the temperature decreases monotonically (Fig. 1a) in clear-sky conditions, if temperature advection is neutral. Another signature of this transition can be seen in short-term variability of surface parameters, highly variable during the noon (associated with thermals) to smaller fluctuations in the night. The weakening of thermals (both magnitude and their vertical extent) in the afternoon reduces the convective turbulence and $\sigma_{\text {WS }}^{2}$ (Fig. 1d). This reduction weakens the downward transport of momentum and low-level wind speed (Fig. 1c) (Mahrt, 1981; Acevedo and Fitzjarrald, 2001). The surface winds also became less gusty during the transition. During the day, when the convective turbulence is active, the low-level moisture gets diluted because of the transport of moisture by turbulence. As the turbulence decreases during the transition, the lowlevel moisture having most of its sources on the Earth's surface increases in the absence of strong mixing (Fig. 1b). On some days, this increase appears as a sudden jump, as also noted by earlier studies (Busse and Knupp, 2012), and on the other days it is more gradual. The wind direction nearly remains the same from $\sim$ 14:00 IST (Indian Standard Time $(\mathrm{IST})=\mathrm{UTC}+05: 30 \mathrm{~h})$ to midnight $($ Fig. 1e)

To understand the transitions aloft, variation of sodar and profiler attributes are examined in detail (Fig. 1f-o). Figure 1 clearly shows the transition of the ABL from a highly convective to a more stable regime. When the convective turbulence is active during the day time, the thermals are clearly apparent as columns of enhanced backscatter in the timeheight SNR plot (Fig. 1k). Though the thermals do not appear clearly in the SNR of sodar in this case, they appear very clearly in other cases. These plumes are also visible in the $w$ plot (Fig. 1i and n) as enhanced up- and down-ward motions with $w$ values exceeding $\pm 2 \mathrm{~m} \mathrm{~s}^{-1}$ and as columns of enhanced turbulence (Fig. 1g and 1). The backscatter for sodar and profiler depends on the refractive index irregularities caused primarily by turbulence-driven temperature and humidity variations. The SNR is, therefore, high during the day, when the convectively driven turbulence is active. Nevertheless, about $2 \mathrm{~h}$ before the sunset, both the intensity and vertical extent of thermals start to decrease continuously till the sunset occurs.. The minimum backscatter (SNR) is seen just before the sunset, mainly due to the weak turbulence. The magnitude of backscatter and vertical extent of sodar data again increase in accordance with the deepening of the inversion layer. As noted by Busse and Knupp (2012), the winds 
Table 3. Major specifications of SODAR, LAWP, $\mathrm{WPR}_{8 \times 8}$ and $\mathrm{WPR}_{16 \times 16}$.

\begin{tabular}{lllll}
\hline Parameter & SODAR & LAWP & WPR $_{16 \times 16}$ & WPR $_{8 \times 8}$ \\
\hline Operating frequency & $1.8 \mathrm{kHz}$ & $1357.5 \mathrm{MHz}$ & $1280 \mathrm{MHz}$ & $1280 \mathrm{MHz}$ \\
Peak power & $100 \mathrm{~W}$ & $1 \mathrm{~kW}$ & $1.2 \mathrm{~kW}$ & $0.8 \mathrm{~kW}$ \\
Antenna array & $1 \mathrm{~m} \times 1 \mathrm{~m}$ & $3.8 \mathrm{~m} \times 3.8 \mathrm{~m}$ & $2.8 \mathrm{~m} \times 2.8 \mathrm{~m}$ & $1.4 \mathrm{~m} \times 1.4 \mathrm{~m}$ \\
Pulse width & $180 \mathrm{~ms}$ & $1 \mu \mathrm{s}($ uncoded) & $4 \mu \mathrm{s}($ coded) & $1 \mu$ (uncoded) \\
Inter pulse period $(\mu \mathrm{s})$ & $9 \times 10^{6}$ & 40 & 55 & 55 \\
No. of coherent integrations & 1 & 70 & 64 & 32 \\
No. of incoherent integrations & 1 & 100 & 20 & 20 \\
No. of FFT points & 4096 & 128 & 1024 & 1024 \\
Beam width (deg) & 4 & 3 & 5 & 6.5 \\
Range resolution $(\mathrm{m})$ & 30 & 150 & 75 & 150 \\
Beam directions* & $\mathrm{N} 16, \mathrm{Z}, \mathrm{E} 16$ & $\mathrm{E} 15, \mathrm{Z}, \mathrm{N} 15$ & $\mathrm{E} 15, \mathrm{~W} 15, \mathrm{Z}, \mathrm{N} 15, \mathrm{~S} 15$ & $\mathrm{E} 10 \mathrm{~N} 10, \mathrm{~W} 10 \mathrm{~S} 10, \mathrm{Z}, \mathrm{W} 10 \mathrm{~N} 10, \mathrm{E} 10 \mathrm{~S} 10$ \\
\hline
\end{tabular}

* E, W, Z, N and S denote eastern, western, zenith, northern and southern directions, respectively, and the number indicates the off-zenith angle.

Table 4. Details of data set 1 grouped as a function of season, showing the total number of days for which data are available, number of discarded days due to cloudy sky/rain or data gaps and number of clear days finally used in the present study. Win, Sum, SWM and NEM stand for, respectively, winter, summer, southwest monsoon and northeast monsoon.

\begin{tabular}{|c|c|c|c|c|c|c|c|c|c|c|c|c|}
\hline \multirow[t]{2}{*}{ Season } & \multicolumn{4}{|c|}{$15 \mathrm{~m}$ tower $(2009-2011)$} & \multicolumn{4}{|c|}{ Sodar (2007-2010) } & \multicolumn{4}{|c|}{$\begin{array}{l}\text { Profiler (1999-2000, } \\
\text { 2010-2011) }\end{array}$} \\
\hline & Win & Sum & SWM & NEM & Win & Sum & SWM & NEM & Win & Sum & SWM & NEM \\
\hline Total no. of days & 113 & 195 & 263 & 221 & 207 & 333 & 414 & 255 & 108 & 238 & 381 & 264 \\
\hline Discarded days & 25 & 55 & 158 & 130 & 105 & 152 & 282 & 189 & 41 & 101 & 227 & 140 \\
\hline Clear days & 88 & 140 & 105 & 91 & 102 & 181 & 132 & 66 & 67 & 137 & 154 & 124 \\
\hline
\end{tabular}

within the nocturnal boundary layer generally decrease during the AT, but increase above the nocturnal boundary layer. It makes the identification of the start time of the AT using wind speed somewhat ambiguous. On the other hand, it is rather easy to identify the start time of the AT from the variations of SNR and $\sigma$. The wind direction does not change much with altitude below $1.5 \mathrm{~km}$ and remains mostly easterly to southeasterly (Fig. $1 \mathrm{j}$ and $\mathrm{o}$ ). It also does not change much with time around the time of sunset (a few hours before and after the time of sunset), ruling out the possibility of advection of different air masses causing the above changes.

When the surface heating reverses to cooling in the evening, both convection and turbulence gradually reduces till the subsequent development of a stable boundary layer with well-defined surface inversion layer. As a result, all state variables at the surface and aloft, manifested primarily by the turbulence, vary considerably during this period. To better depict this variability, MBLM- $\left(T, r, \sigma_{\mathrm{WS}}^{2}\right.$ and $\Delta T\left(T_{5^{-}}\right.$ $T_{10}$ indicating the stability of the lower ABL; the suffixes 5 and 10 indicate the height of temperature measurements in $\mathrm{m})$ ), sodar- and profiler-derived state variables (SNR and $\sigma$ at three representative levels; 150,300 and $450 \mathrm{~m}$ for sodar and 900,1500 and $2100 \mathrm{~m}$ for profiler) during the period 15:0021:00 IST are plotted in Fig. 2. To minimize random fluctuations and the chosen level more representative, the data are averaged both in time ( 5 min for sodar and no temporal integration for profiler) and height (three heights centred on the chosen level). The time series surface data are then low-pass filtered using local regression using weighted linear least squares and a first-order polynomial model (using the function "lowess" in matlab). On 11 May 2010, the temperature (Fig. 2a) starts to decrease monotonically, at the rate of $1-1.5^{\circ} \mathrm{C}$ per $1 \mathrm{~h}$, from $16: 10 \mathrm{IST}$ (dashed line), $152 \mathrm{~min}$ prior to the time of sunset (solid vertical black line). Though the temperature decrement starts little early, but is not consistent and also weak in magnitude. Another surface characteristic showing a significant change during the AT is the mixing ratio (Fig. 2b), which clearly shows a gradual increase from 16:10 IST. The temperature gradient (Fig. 2c) also reverses from positive to negative few minutes after the $5 \mathrm{~m}$ level temperature starts to decrease. The wind variance (Fig. 2d), representing small-scale wind fluctuations and turbulence, also shows a decreasing trend from 16:25 IST.

The sodar and profiler backscatter, depends primarily on turbulent irregularities of refractive index, decreases with the waning of sensible heat flux (and thermals) during the afternoon transition. On 11 May 2010, the SNR of sodar starts to decrease $\sim 2 \mathrm{~h} 40 \mathrm{~min}$ prior to the time of sunset at all heights. Interestingly, the start time of SNR reduction shows height dependence with higher altitudes showing the reduc- 

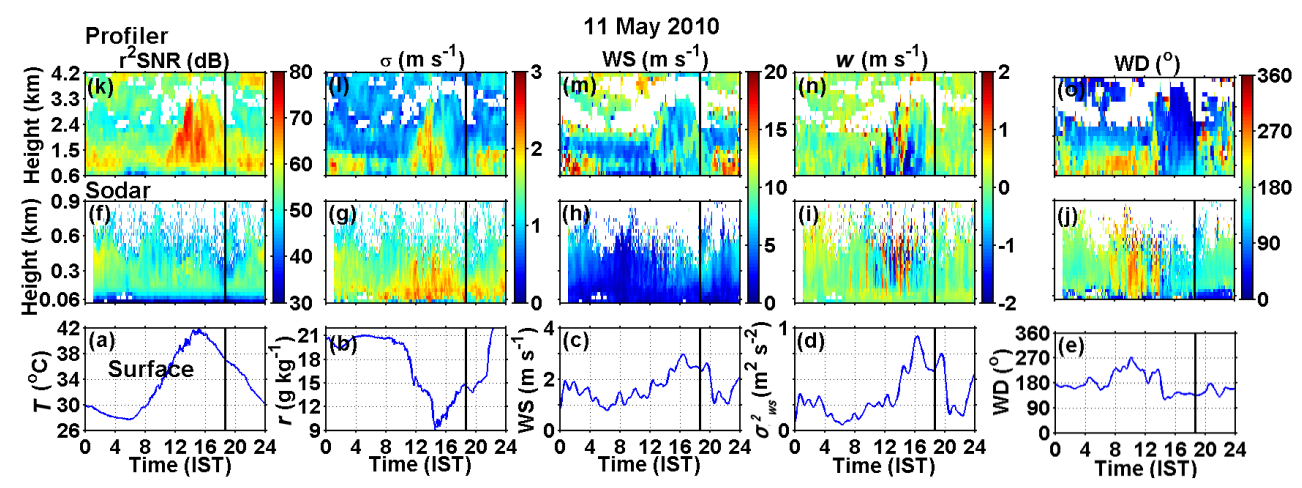

Figure 1. Diurnal variation of state variables at the surface and aloft on 11 May 2010, MBLM-derived surface (a) $T$, (b) $r$, (c) WS (d) $\sigma_{\text {WS }}^{2}$ and (e) WD and sodar-derived (f) range-corrected SNR, (g) $\sigma$, (h) WS, (i) $w$ and (j) WD. (k-o) Same as (f-j), except for profiler-derived state variables. The solid vertical line indicates the time of sunset.

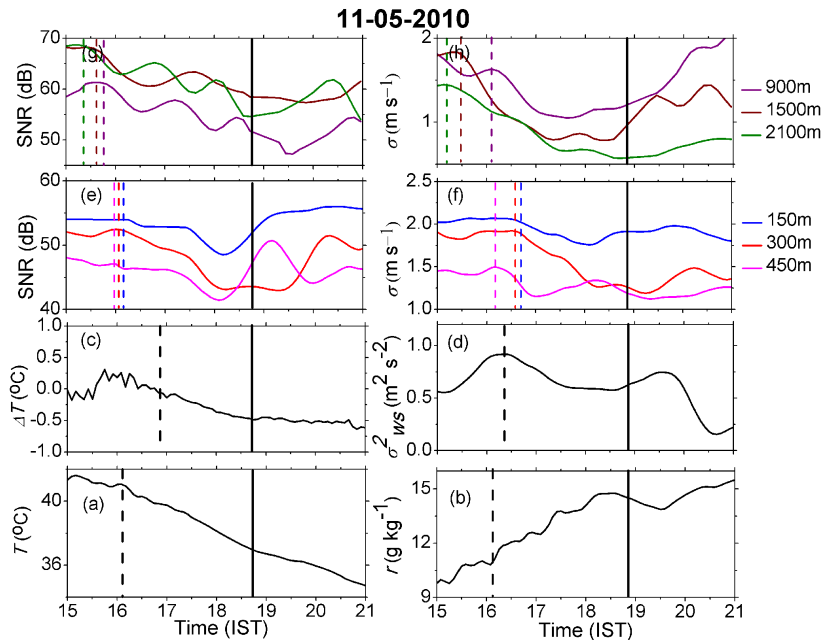

Figure 2. Temporal variation of state variables (at the surface and aloft) a few hours before and after the time of sunset (indicated with a black solid vertical line). Temporal variation of MBLM-derived (a) $T$, (b) $r$, (c) $\Delta T$ and (d) $\sigma_{\mathrm{WS}}^{2}$, sodar-derived (e) range-corrected SNR and (f) $\sigma$ and profiler-derived (g) range-corrected SNR and (h) $\sigma$. The sodar- and profiler-derived parameters are plotted at three representative levels each $(150,300$ and $450 \mathrm{~m}$ for sodar and 900, 1500 and $2100 \mathrm{~m}$ for profiler). Vertical dashed lines indicate the start time of the transition as identified by different state variables.

tion earlier. The SNR minimum is observed $10-20$ min before the sunset at all heights, mainly due to the reduction in turbulent fluctuations in temperature. Nevertheless, the SNR increases again after the sunset, following the formation of an inversion layer. The $\sigma$ (Fig. 2f) variations are quite similar to that of SNR during the transition. The $\sigma$ shows a decreasing trend $2 \mathrm{~h} \mathrm{10-20} \mathrm{min} \mathrm{prior} \mathrm{to} \mathrm{the} \mathrm{sunset,} \mathrm{whereas} \mathrm{its} \mathrm{minimum}$ is observed 10-30 min from the time of sunset. The profiler SNR and $\sigma$ variations are similar to that of sodar, except that their reduction starts little early. The profiler SNR and $\sigma$ start to decrease $\sim 3 \mathrm{~h}$ prior to the time of sunset. Also, the SNR and $\sigma$ minima are observed at around the time of sunset. It is very interesting to note the height dependency in the time at which state variables show large variation; i.e., it is seen first in profiler attributes, then in sodar attributes and finally in surface parameters.

\subsection{Distributions for start time of transition with reference to the time of sunset}

It is clear from the case study that surface parameters and sodar/profiler attributes show large variations during the AT. The first and foremost problem, therefore, is to properly and objectively identify the start time of the AT from these state variables. It is also important to recognize the state variable that unambiguously identifies the start time of the transition. As seen in case studies, state variables like $T, \Delta T, r$ and $\sigma_{\mathrm{WS}}^{2}$ at the surface and SNR and $\sigma$ aloft can be used for this purpose. For identifying the start time of AT, 19 days on which measurements of all instruments (MBLM, sodar and profiler) are available are considered. The start time of AT is identified manually from temporal variation of each state variable (like those shown in Fig. 2). The temporal gradients are estimated for each state variable from all 19 cases, which are then finally used to fix the thresholds. The start time of AT is identified from the variation of each state variable as follows.

Temperature: the time at which $T$ starts to decrease by $\geq 0.5^{\circ} \mathrm{C}$ in $30 \mathrm{~min}$.

Water vapor mixing ratio: the time at which $r$ increases by $\geq 0.5 \mathrm{~g} \mathrm{~kg}^{-1}$ in $30 \mathrm{~min}$.

Wind variance: the time at which $\sigma_{\mathrm{WS}}^{2}$ decreases by $\geq 0.1 \mathrm{~m}^{2} \mathrm{~s}^{-2}$ in $30 \mathrm{~min}$.

Temperature gradient: the time at which $\Delta T$ becomes positive to negative and remains negative for at least an hour.

SNR: the time at which SNR decreases by $>1 \mathrm{~dB}$ in 30 min.

Spectral width: the time at which $\sigma$ decreases by $\geq 0.1 \mathrm{~m} \mathrm{~s}^{-1}$ in $30 \mathrm{~min}$. 
Note that all the above conditions should hold good for at least an hour from the start time of the transition. Also, all the above conditions are checked only in the data during 15:00-20:00 IST.

First, the average behavior of the start time of the AT, as identified by selected state variables, with reference to the sunset (i.e., start time of the AT - time of sunset) has been studied at the surface and aloft. The distributions (from data set 1) for the start time of the AT with reference to the sun-

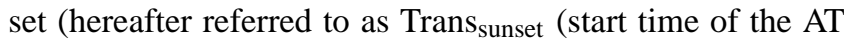
- time of sunset)) as obtained by various state variables are shown in Fig. 3. These distributions are shown as boxplots, where the box comprises $50 \%$ of values (25th and 75 th percentiles) and whiskers represent 5th and 95th percentile values. On average, $\sigma_{\text {WS }}^{2}$ and $T$ show the first signature of the AT among all surface state variables (Fig. 3a), 1 h 40 min prior to the time of sunset, followed by $\Delta T$ ( $1 \mathrm{~h} 18 \mathrm{~min}$ before sunset). The last characteristic for the transition is seen in $r$ as a gradual increase (or jump) occurring $1 \mathrm{~h} 10 \mathrm{~min}$ prior to the time of sunset. The signature of the transition can be seen as early (late) as 165 (45) min before (after) the sunset in $\sigma_{\mathrm{WS}}^{2}(r)$ on some days. Except for temperature, all other surface state variables show the signature of the transition even after the sunset. Though not many such cases are found at Gadanki (can be seen from Fig. 3a), late transitions are not uncommon, as they are widely reported elsewhere (Acevedo and Fitzjarrald, 2001). The distribution of Trans sunset $_{\text {is wider }}$ for $r$ than for any other state variable, indicating that the jump in $r$ occurs at different timings with reference to the time of sunset. On the other hand, the start time of the AT as obtained by $T$ is relatively consistent throughout the year, as evidenced by the narrow distribution (Fig. 3a).

Figure 3b-g shows distributions for Trans sunset $_{\text {as }}$ identified by selected sodar and profiler attributes (SNR and $\sigma$ ) at three selected altitudes (150, 300 and $450 \mathrm{~m}$ for sodar and 900,1500 and $2100 \mathrm{~m}$ for profiler). At any particular altitude, both SNR and $\sigma$ show the signature of the transition around the same time. Though small differences exist, they are not significant. Nevertheless, the identification of the transition start time is somewhat easy with SNR and is also consistent, as evidenced by its relatively narrow distribution.

As seen in the case study, the mean start time of the AT also shows height dependency and follows top-to-bottom evolution; i.e., the signature of the AT is seen first in the profiler data ( $\sim 2 \mathrm{~h} 40 \mathrm{~min}$ before the time of sunset), then in sodar data ( $\sim 2 \mathrm{~h}$ before the time of sunset) and finally in MBLM measurements. Angevine (2008) also noted the deterioration of the ABL structure aloft with the wind profiler preceding the start time of the AT at the surface. It contradicts the general perception that the entire ABL is controlled primarily by the underlying Earth's surface and the start time of transition should follow a bottom-up evolution. It is true that surface forcing is the defining mechanism during the day, but it seems not the case during the transition, the time during which other forces could also be important.

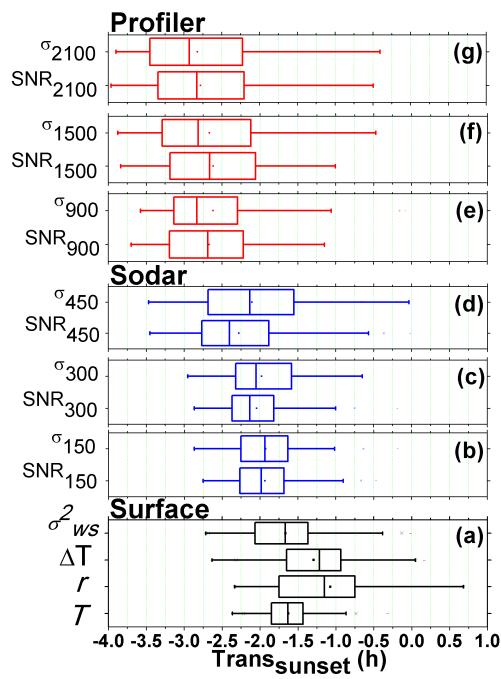

Figure 3. Distributions (in terms of boxplot) of Trans sunset $_{\text {(n) start }}$ time of AT - time of sunset) for different state variables, depicting the behavior of the transition start time with reference to the

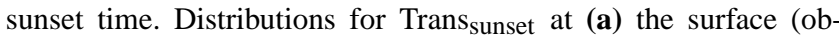
tained from $T, r, \Delta T$ and $\sigma_{W S}^{2}$ ), (b-d) 150,300 and $450 \mathrm{~m}$, respectively (obtained from sodar-derived range-corrected SNR and $\sigma)$ and $(\mathbf{e}-\mathbf{g})$ 900, 1500 and $2100 \mathrm{~m}$, respectively (obtained from profiler-derived range-corrected SNR and $\sigma$ ).

A sensitivity analysis is carried out to know the impact

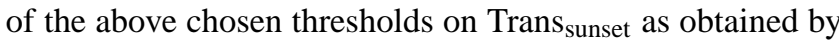
different state variables. The chosen thresholds are varied by $\pm 20 \%$ in steps of $10 \%$ and the mean Trans sunset $_{\text {as obtained }}$ by different state variables is estimated at different altitudes.

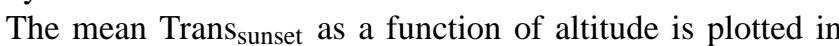
Fig. 4, which clearly shows that the important results do not change much, even if we vary the thresholds by $\pm 20 \%$. For

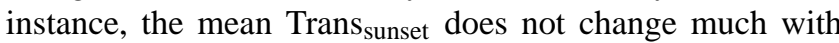
the variation of thresholds. Also, the height dependence of Trans $_{\text {sunset }}$ is strikingly apparent with all used thresholds. It

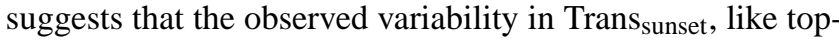
to-bottom evolution, is not an artefact arising due to the chosen thresholds. Regarding the usability of these thresholds at other sites, it appears (from Fig. 4) that they possibly can be used at other tropical sites, which are in similar climatic conditions as Gadanki region. Although we expect similar variations in most of the state parameters at mid- and highlatitudes, the magnitude of variation could be different because of the differences in the solar zenith angle and rate of reduction of solar radiation during the transition. Therefore, some tuning of thresholds may be required at different latitudes.

\subsection{Seasonal variation in the start time of the transition}

Gadanki experiences different seasonal patterns: very hot and dry summer, hot and rainy southwest monsoon, cool and rainy northeast monsoon and cool and dry winter. These sea- 


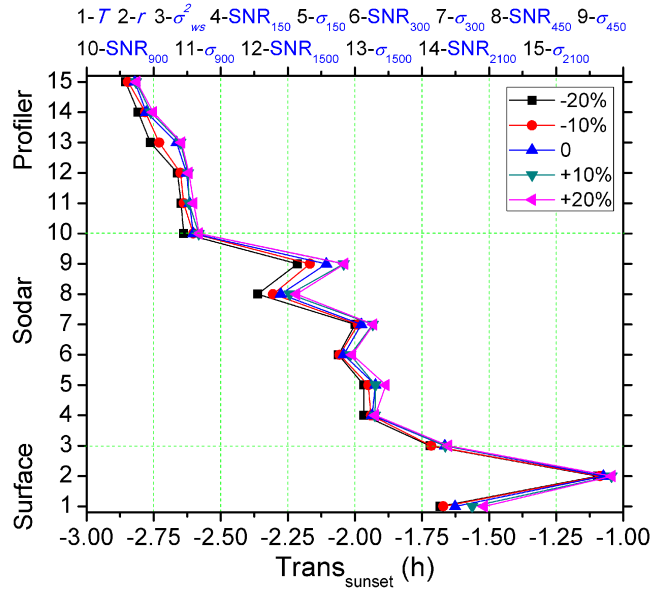

Figure 4. Variation of mean Trans sunset as obtained by different state variables for different thresholds, depicting the sensitivity of thresholds used in the present study to the start time of the transition.

sonal factors (solar exposure, synoptic flow, soil condition, etc.) will have a different impact on the ABL, in general, and transitions, in particular. Therefore, the distributions of Trans $_{\text {sunset }}$ for different seasons (Fig. 5) have been studied to understand the impact of the above factors on the start time of the transition. Figure 5a-d reveals that the order in which the surface state variables show the transition remain nearly the same (the monsoon season is an exception), but their occurrence time with reference to the sunset varies considerably. Although reduced compared to the total data (Fig. 3), the distribution, representing the variability within the season, of the transition start time for each state variable is quite wide.

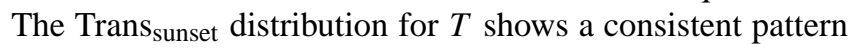
regardless of the season, with small variability within the season, and the transition starts $80-100$ min prior to the time of sunset. Nevertheless, it exhibits a clear seasonal variation with dry seasons (winter and summer) showing the transition early ( $\sim 110 \mathrm{~min}$ prior to the sunset time) compared to rainy seasons ( $80 \mathrm{~min}$ prior to the sunset time). The distributions for other state variables also show some seasonal variation, with warm seasons showing the transition a little earlier than cold seasons. But, their distributions are much wider than the observed weak seasonal variation. Among all state variables, the Trans $s_{\text {sunset }}$ distribution for $r$ shows not only large seasonal variability, but also a wide distribution, indicating the highly variable nature of the $r$ jump (i.e., starts at different timings with reference to the sunset).

Two representative heights, $300 \mathrm{~m}$ from the sodar and $1500 \mathrm{~m}$ from the wind profiler, are chosen to study the seasonal variation in the transition start time aloft (Fig. 5e-1). Like in Fig. 3, there is not much difference in the start time of transition by SNR and $\sigma$ in any season and at any particular altitude. Two observations are strikingly apparent from Fig. 5.
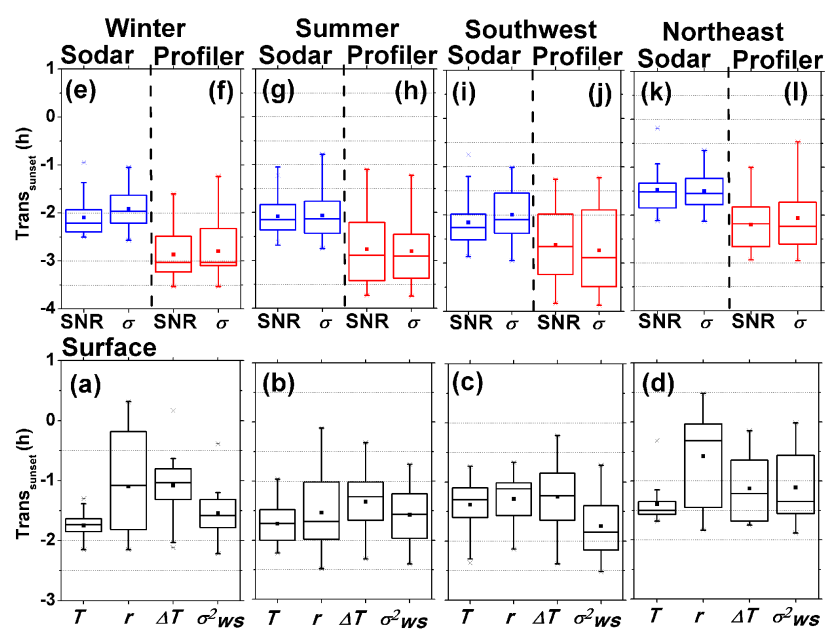

Figure 5. The distributions of Trans sunset as obtained by different surface state variables for (a) winter (b) summer, (c) southwest monsoon and (d) northeast monsoon, depicting the seasonal variability in the start time of the transition. The distributions for

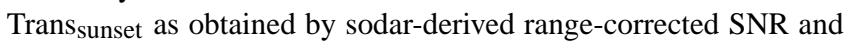
$\sigma$ at $300 \mathrm{~m}$ for (e) winter, (g) summer, (i) southwest monsoon and (k) northeast monsoon, respectively. (f), (h), (j) and (l) are the same as (e), (g), (i) and (k), except for profiler-derived range-corrected SNR and $\sigma$ at $1500 \mathrm{~m}$.

1. Both profiler- and sodar-derived start times of transition show some seasonal variation with delayed transition during the northeast monsoon, consistent with the seasonal variation at the surface.

2. Irrespective of the season, the height dependency in the transition start time is intact. Both these issues are discussed in detail in Sect. 4.

\section{Discussion}

The four major questions related to the start time of transition that the paper tries to answer are (i) which state variable better identifies it, (ii) does it exhibit any seasonal variation, (iii) does it show any height dependency, and (iv) which physical mechanism is responsible for the observed height variation of Trans sunset? ?

i. Among all state variables, the decrease in temperature at the surface and SNR aloft are strikingly apparent in all case studies, which makes them ideal for identifying the start time of the AT. Furthermore, the distributions of Trans $_{\text {sunset }}$ for $T$ and SNR are somewhat consistent and narrower than that for other state variables. Although several earlier studies employed reversal of sign in surface heat flux as a criterion for transition (Lothon et al., 2014, and references therein), it is now well known that such a reversal does not always occur during the transition (Busse and Knupp, 2012). The formation of an 
inversion depends on several other factors and therefore the formation of inversion alone cannot be used to define the transition. A few studies used deceleration of low-level wind as a criterion for identifying the transition (Mahrt, 1981). The above criterion works well in the lower portion of ABL, but fails above the nocturnal boundary layer, where the wind accelerates in the frictionless fluid. Therefore, $T$ at the surface and SNR aloft can be used to identify the start time of the transition, as also suggested by Edwards et al. (2006).

ii. The start time of the transition as defined by different state variables shows some seasonal variation, with late transitions during the northeast monsoon season. Though Gadanki receives $55 \%$ of the annual rainfall in the southwest monsoon, raising instantaneous soil moisture levels, the high insolation and temperatures immediately consume the soil moisture for latent heating. On the other hand, this region also gets a good amount of rainfall during the cool northeast monsoon (Rao et al., 2009). The soil moisture levels, therefore, remain high in this season. It is known from earlier studies that the abundance of soil moisture not only produces shallow ABL, but also delays the growth of the ABL (Sandeep et al., 2014). It appears from present observations that not only the growth but also the descent (or transition) is getting delayed due to the excess soil moisture.

iii. The total and seasonal distributions of Trans sunset $_{\text {for }}$ different state variables at the surface and aloft clearly show the height dependency in the start time of transition, following a top-to-bottom evolution. It is known from the literature that there exists an apparent contradiction between those who think the transition starts in the afternoon at high levels (Angevine, 2008) and others who believe the AT occurs around the sunset and follows a bottom-up evolution. The present study supports the former view, as similar evolution is seen in total and seasonal plots (Figs. 3 and 5). During the AT, when the surface buoyancy flux decreases toward zero, the influence of other competing processes like advection, and entrainment becomes relatively more important (Bosveld et al., 2014). Therefore an attempt has been made to estimate these fluxes (buoyancy and entrainment) to understand their roles in the observed height dependency in transition start time.

The ratio between the vertical kinematic eddy heat flux at the top of the ABL and kinematic eddy heat flux at the surface (entrainment ratio) (Sun and Wang, 2008), as given below, therefore, becomes a fundamental and decisive parameter.

$A_{R}=-\frac{\overline{\left(w^{\mid} \Theta^{\mid}\right)_{z i}}}{\overline{\left(w^{\mid} \Theta^{\mid}\right)_{s}}}$
The heat flux at the top of ABL (or entrainment flux) is estimated following Angevine (1999). The entrainment can occur due to any or all of these factors: (1) when there is a shift in the ABL height (2) due to wind shear at the surface, (3) due to wind shear at the top of the ABL and (4) advection.

$$
\begin{aligned}
-\left(\overline{w^{\mid} \Theta \mid}\right)_{z i} & =A_{0}+\left(A_{2} u_{*}^{2} u+A_{3} \Delta u_{h}^{3}\right) \cdot\left(\theta_{\mathrm{vo}} / g d_{1}\right) \\
& +\left(U \frac{\partial T}{\partial x}+V \frac{\partial T}{\partial y}\right)
\end{aligned}
$$

where $u_{*}$ is the friction velocity, $u$ the surface horizontal velocity ( $8 \mathrm{~m}$ in our case), $\Delta u_{h}$ the wind shear at the top of ABL, $g$ the acceleration due to gravity, $\theta_{\mathrm{vo}}$ the virtual potential temperature at the surface, $d_{1}$ is the depth of entrainment zone and $A_{2}$ and $A_{3}$ are empirical constants, $A_{2}=0.005$ and $A_{3}=0.01$ (Stull, 1976). For the estimation of advection (last term in Eq. 2), the temperature $(T)$, horizontal distance in zonal and meridional planes ( $\partial x$ and $\partial y$, respectively, and is equal to $0.5^{\circ}$ ) and zonal $(U)$ and meridional $(V)$ wind velocities near the top of ABL are taken from ECMWF Interim Reanalysis data (Dee et al., 2011). $A_{0}$ is the entrainment flux in the absence of any mechanical term contribution and is expressed as $w_{\mathrm{e}} \Delta \Theta, w_{\mathrm{e}}$ is the entrainment velocity and is estimated as follows.

$w_{\mathrm{e}}=\frac{\mathrm{d} z_{i}}{\mathrm{~d} t}-\bar{w}$

where $\bar{w}$ is the average vertical velocity at the top of the ABL and $\Delta \theta$ the vertical gradient in $\theta_{\mathrm{v}}$ at the top of the ABL. As seen above, the timescales and space scales of different entrainment processes cover a wide range, which makes it difficult to measure or model accurately (Angevine, 1999). Although it is possible to quantify the entrainment flux from the heat budget equation (Eq. 2), the uncertainties in the basic parameters (for instance, those in the advection term and $w$ ) hamper the accuracy of the flux. Therefore, as also pointed out by Angevine (1999), these numbers need to be considered as the "best available estimates".

It is clear from the above equations that profiles of meteorological parameters such as $T, \mathrm{RH} / r$ and $w$ are essential to estimate the entrainment ratio. Though $w$ can be obtained continuously from the wind profiler, continuous measurement of $T$ and $\mathrm{RH} / r$ at the top of the ABL is a difficult task. We, therefore, considered two 3-day campaign data (one each from the southwest monsoon and winter), wherein radiosonde ascents were made once in $\sim 3 \mathrm{~h}$, for a detailed study (data set 2).

Figure $6 \mathrm{a}-\mathrm{c}$ shows the time-height variation of SNR, $w$ and $\sigma$ on 22 July 2011, depicting the typical diurnal evolution of the ABL during the campaign period. The $\theta_{\mathrm{v}}$ profiles during the morning-evening (at 08:24, 11:54, 14:25 and 17:15 IST) period are shown in Fig. 6d to depict the height of the ABL (and also the gradients in $\theta_{\mathrm{v}}$ at the top of the $\mathrm{ABL}$ ). Clearly, the height of the ABL as obtained by the profiler (shown with dots on the SNR plot) and radiosonde (the 


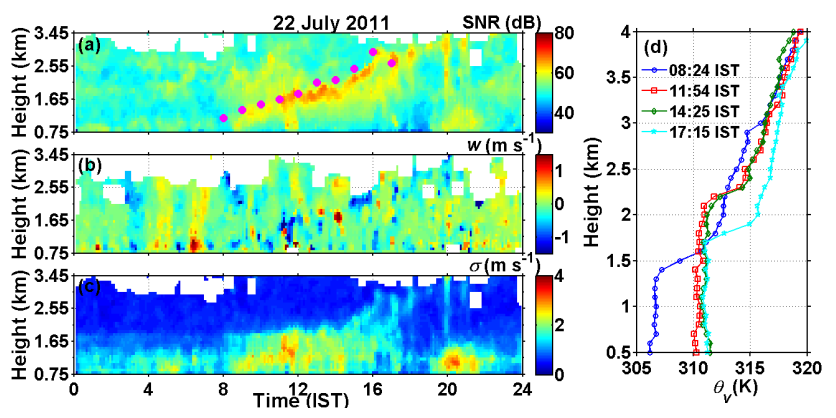

Figure 6. Diurnal variation of profiler attributes (a) range-corrected SNR (b) $w$ and (c) $\sigma$ on 22 July 2011, illustrating the evolution of the ABL and afternoon transition. (d) The vertical variation of radiosonde-derived $\theta_{\mathrm{V}}$ at $\sim 3 \mathrm{~h}$ intervals. The solid symbols in (a) indicate the height of the ABL.

gradient in $\theta_{\mathrm{v}}$ profile) corresponds well. The agreement between them is also good in the diurnal variation, with both the measurements showing a shallow ABL in the morning and evening transition periods and a deep ABL during the day, when the ABL is convectively active.

The start time of AT as seen by different state variables at the surface and aloft on all days during the two campaigns is shown in Fig. 7a and b. It clearly reiterates the height dependency of the start time of AT seen in Figs. 2-5; i.e., the start time of AT observed by the profiler precedes surface state variables on all days and in both seasons. Though the same pattern is seen on all days, the time at which the transition starts varies considerably from day to day.

The entrainment flux at the top of $\mathrm{ABL}$ is estimated by combining the measurements of radiosonde $\left(\Delta \theta, d_{1}\right)$, profiler $\left(w, \Delta u_{h}\right)$, MBLM $\left(u, \theta_{\mathrm{vo}}\right)$ and a meteorological flux tower $\left(u_{*}\right)$ with ECMWF interim data (advection term). The sensible heat flux and $u_{*}$ at the surface required to quantify the entrainment ratio (Eq. 1) are estimated following the eddy covariance method by using $20 \mathrm{~Hz}$ resolution ultrasonic anemometer measurements at $8 \mathrm{~m}$ level. These fluxes are evaluated at $30 \mathrm{~min}$ resolution.

Figure $8 \mathrm{a}$ and $\mathrm{b}$ shows the sensible and entrainment fluxes at $\sim 3 \mathrm{~h}$ resolution during the day, depicting the forcing on the ABL from bottom and top. The sensible heat flux varies considerably during the day, with fluxes varying from $0.15-0.25 \mathrm{~K} \mathrm{~ms}^{-1}$ around noon $(\sim 11: 00$ and $\sim 14: 00$ IST) to $0.02-0.07 \mathrm{~K} \mathrm{~ms}^{-1}$ during the morning and evening transitions ( $\sim$ 08:00 and $\sim$ 17:00 IST). On the other hand, the entrainment flux neither changes drastically during the day nor shows a clear diurnal cycle (compared to sensible heat flux). The magnitude of entrainment flux depends mostly on the first term in Eq. (2), while the shear (2 and 3 terms in Eq. 2) contributes very little to the total entrainment flux (not shown). Since the buoyancy flux changes considerably, the entrainment ratio varies significantly during the course of the day. The entrainment ratio increases to $0.5-1.1$ during the morning and evening transitions. Therefore, it is very clear
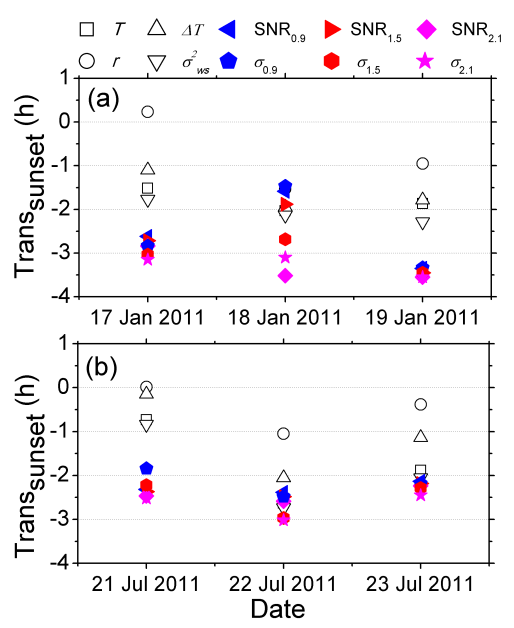

Figure 7. The start time of the AT with reference to the time of sunset as obtained by different state variables at the surface and aloft during (a) 17-19 January 2011 and (b) 21-23 July 2011.

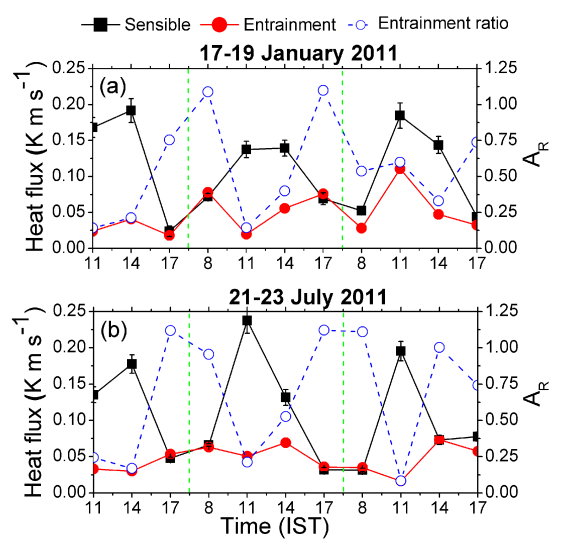

Figure 8. Sensible and entrainment fluxes (left axis) and entrainment ratio (right axis) estimated at $\sim 3 \mathrm{~h}$ intervals during (a) 1719 January 2011 and (b) 21-23 July 2011, indicating the forcings on the ABL from the bottom and top.

from these observations that the forcing from the top (i.e., entrainment flux) becomes very important, when the buoyancy flux is weak (i.e., during the transitions and night). A few earlier studies also underscored the importance of buoyancy flux in altering the structure of the ABL. The entrainment not only modifies the top of the ABL but also impacts the entire depth of the ABL (Lohou et al., 2010). Caughey and Kaimal (1977), have shown experimentally that the heat flux descents suddenly during the transition, approximately an hour before the sunset, and the reversal of heat flux (from positive to negative) first occurs at higher altitudes and then propagates downwards to the surface, indicating the importance of entrainment heat flux in the top-to-bottom evolution of the transition. Also, with continuous waning of sensible heat flux during the AT, both the vertical extent and strength of thermals (can be seen in Figs. 1 and 6) decrease 
monotonously. At the same time, the surface forcing (heating) remains good enough to maintain the turbulence close to the surface and therefore does not show the signature of transition, but delays it at the surface (Angevine, 2008).

\section{Conclusions}

This study presents a comprehensive view of the AT in terms of understanding the variability of different state variables using a suite of in situ and remote sensing measurements at Gadanki. The study aims to address the following issues related to the start time of AT with a unique and statistically robust data set ( $\sim 3$ years). Which parameter first shows the signature of transition at the surface and aloft? Which parameter better defines or identifies it? How does it vary with altitude and season? Which physical mechanism explains the observed vertical variation of transition?

i. Among the surface state variables, the signature of transition is first seen in $\sigma_{\mathrm{WS}}^{2}$ and $T$ data, both of which start decreasing monotonically $\sim 100 \mathrm{~min}$ prior to the time of sunset. The $r$ increase is the last signature of transition, while the reversal of $\Delta T$ variation from positive to negative falls in between these extremes. Aloft, both SNR and $\sigma$ identify the start of the AT at the same time, 120-160 min prior to the time of sunset, depending on the height considered. The observed mean start time of the AT ( $2 \mathrm{~h}$ prior to the sunset), obtained from SNR and $\sigma$ variations, matches well with that obtained by Mahrt (1981), who used horizontal wind reduction for identifying the transition.

ii. At the surface, the start time of AT can be discerned more easily from variations of $T$ than from that of $\sigma_{\mathrm{WS}}^{2}, r$ and $\Delta T$. While $\sigma_{\mathrm{WS}}^{2}$ and $\Delta T$ variations show large modulations with time, $r$ variation is ambiguous at times. Also, the temperature reduction is more consistent with relatively narrow distribution and occurs always before the sunset. Aloft, SNR variation is robust in identifying the transition compared to ambiguous variations in horizontal wind velocity (decreases at lower altitudes and increases at higher altitudes).

iii. The start time of the AT as defined by different state variables shows some seasonal variation, with delayed transitions during the northeast monsoon at the surface and aloft. Though there is some seasonal variation in the start time of the AT relative to sunset time, the order in which the signature of the AT is seen in different state variables (first in $T$, and $\sigma_{\mathrm{WS}}^{2}$ followed by $\Delta T$ and $r$ ) remained nearly the same in all seasons.

iv. Interestingly, the start time of the AT exhibits a clear height dependency; i.e., the signature of the transition is seen first in profiler attributes $(\sim 160 \mathrm{~min})$ followed by sodar attributes $(\sim 120 \mathrm{~min})$ and finally in surface state variables $(\sim 100 \mathrm{~min})$, suggesting that the transition follows a top-to-bottom evolution (Angevine, 2008). The fact that the first signatures of the transition are seen at higher altitudes by profiler/sodars than at the surface suggests that forces other than the buoyancy could also play an important role during the transition. With continuous waning of sensible heat flux (and surface forcing) during the AT, both the vertical extent and the strength of thermals decrease steadily (as seen in Figs. 1 and 6), triggering the descent of the ABL or the transition. However, the surface heating is good enough to maintain the state variables and delay the decrease in $T$ and $\sigma_{\mathrm{WS}}^{2}$ (considered to be the signatures of the transition). Furthermore, the impact of forcings from the top and bottom on the ABL is studied by quantifying the sensible and entrainment fluxes, using a flux tower and profiler-radiosonde measurements, respectively. Though the sensible heat flux varied significantly during the day, the entrainment flux remained nearly the same throughout the day. The entrainment ratio increases considerably during the morning and evening transitional periods, primarily due to the weak sensible heat flux. Therefore, the entrainment flux appears to be playing a major role during the transition period (and in the night) during which the sensible heat flux continuously weakens.

Acknowledgements. The authors would like to thank M. Venkat Ratnam for providing the GPS radiosonde used in the present study (experiments are conducted under the special campaign of tropical tropopause dynamics (TTD) as a part of the CAWSES-Phase II program, India).

Edited by: E. Pardyjak

\section{References}

Acevedo, O. C. and Fitzjarrald, D. R.: The early evening surfacelayer transition: Temporal and spatial variability, J. Atmos. Sci., 11, 2650-2667, 2001.

Anandan, V. K., Shravankumar, M., and Srinivasarao, I.: First results of experimental tests of newly developed NARL phased array Doppler sodar, J. Atmos. Ocean. Tech., 25, 1778-1784, 2008.

Angevine, W. M.: Entrainment results including advection and case studies from the Flatland boundary layer experiments, J. Geophys. Res., 104, 30947-30963, 1999.

Angevine, W. M.: Transitional, entraining, cloudy, and coastal boundary layers, Acta Geophys., 56, 2-20, 2008.

Beare, R. J., Edwards, J. M., and Lapworth, A. J.: Simulation of the observed evening transition and nocturnal boundary layers: Large-eddy modelling, Q. J. Roy. Meteor. Soc., 132, 61-80, 2006.

Bonin, T., Phillip, C., Brett, Z., and Fedorovich, E.: Observations of the early evening boundary-layer transition using a small un- 
manned aerial system, Bound.-Lay. Meteorol., 146, 119-132, 2013.

Bosveld, F. C., Baas, P., Steeneveld, G. J., Holtslag, A. A. M., Angevine, W. M., Bazile, E., Bruijn, E. I. F. D., Deacu, D., Edwards, J. M., Michael, E. K., Larson, V. E., Pleim, J. E., Raschendorfer, M., and Svensson, G.: The third GABLS intercomparison case for evaluation studies of boundary-layer models. Part B: Results and process understanding, Bound.-Lay. Meteorol., 152, 157-187, doi:10.1007/s10546-014-9919-1, 2014.

Brazel, A. J., Fernando, H. J. S., Hunt, J. C. R., Selvor, N., Hedquist, B. C., and Pardyjak, E.: Evening transition observations in Phoenix, Arizona, J. Appl. Meteorol., 44, 99-112, 2005.

Burba, G.: Eddy covariance method for scientific, industrial, agricultural, and regulatory applications, LI-COR Biosciences, Nebraska, 331 pp., 2013.

Busse, J. and Knupp, K.: Observed characteristics of the afternoonevening boundary layer transition based on sodar and surface data, J. Appl. Meteorol. Clim., 51, 571-582, 2012.

Caughey, S. and Kaimal, J.: Vertical heat flux in the convective boundary layer, Q. J. Roy. Meteor. Soc., 103, 811-815, 1977.

Dee, D. P., Uppala, S. M., Simmons, A. J., Berrisford, P., Poli, P., Kobayashi, S., Andrea, U., Balmaseda, M. A., Balsamo, G., Bauer, P., Bechtold, P., Beljaar, A. C., van de Berg, L., Bidlot, J., Bormann, N., Delsol, C., Dragani, R., Fuentes, M., Geer, A. J., Haimberger, L., Healy, S. B., Hersbach, H., Hólm, E. V., Isaksen, L., Kållberg, P., Höhler, M., Matricardi, M., McNally, A. P., Monge-Sanz, M., Morcrette, J.-J., Park, B.-K., Peubey, C., de Rosnay, P., Tavolato, C., Thépaut, J.-N., and Vitart, F.: The ERAInterim reanalysis: configuration and performance of the data assimilation system, Q. J. Roy. Meteor. Soc., 137, 553-597, 2011.

Edwards, J. M., Beare, R. J., and Lapworth, A. J.: Simulation of the observed evening transition and nocturnal boundary layers: Single-column modelling, Q. J. Roy. Meteor. Soc., 132, 61-80, 2006.

Fernando, H. J. S., Verhoef, B., Sabatino, S. Di., Leo, L. S., and Park, S.: The Phoenix evening transition flow experiment (TRANSFLEX), Bound.-Lay. Meteorol., 147, 443-468, doi:10.1007/s10546-012-9795-5, 2013.

Grant, A. L. M.: An observational study of the evening transition boundary-layer, Q. J. Roy. Meteor. Soc., 123, 657-677, 1997.

Grimsdell, A. W. and Angevine, W. M.: Observations of the afternoon transition of the convective boundary layer, J. Appl. Meteorol., 41, 3-11, 2002.

Klein, P. M., Hu, X. M., and Xue, M.: Impacts of mixing processes in nocturnal atmospheric boundary layer on urban ozone concentrations, Bound.-Lay. Meteorol., 150, 107-130, doi:10.1007/s10546-013-9864-4, 2014.

Lohou, F., Said, F., Lothon, M., Durand, P., and Serça, D.: Impact of boundary layer processes on near-surface turbulence within the West Africa monsoon, Bound.-Lay. Meteorol., 136, 1-23, 2010.

Lothon, M., Lohou, F., Pino, D., Couvreux, F., Pardyjak, E. R., Reuder, J., Vilà-Guerau de Arellano, J., Durand, P, Hartogensis, O., Legain, D., Augustin, P., Gioli, B., Lenschow, D. H., Faloona, I., Yagüe, C., Alexander, D. C., Angevine, W. M., Bargain, E, Barrié, J., Bazile, E., Bezombes, Y., Blay-Carreras, E., van de Boer, A., Boichard, J. L., Bourdon, A., Butet, A., Campistron, B., de Coster, O., Cuxart, J., Dabas, A., Darbieu, C., Deboudt, K., Delbarre, H., Derrien, S., Flament, P., Fourmentin, M., Garai, A., Gibert, F., Graf, A., Groebner, J., Guichard, F., Jiménez, M.
A., Jonassen, M., van den Kroonenberg, A., Magliulo, V., Martin, S., Martinez, D., Mastrorillo, L., Moene, A. F., Molinos, F., Moulin, E., Pietersen, H. P., Piguet, B., Pique, E., RománCascón, C., Rufin-Soler, C., Saïd, F., Sastre-Marugán, M., Seity, Y., Steeneveld, G. J., Toscano, P., Traullé, O., Tzanos, D., Wacker, S., Wildmann, N., and Zaldei, A.: The BLLAST field experiment: Boundary-Layer Late Afternoon and Sunset Turbulence, Atmos. Chem. Phys., 14, 10931-10960, doi:10.5194/acp14-10931-2014, 2014.

Mahrt, L.: The early evening boundary layer transition, Q. J. Roy. Meteor. Soc., 107, 329-343, 1981.

Nadaeau, D. F., Pardyjak, E. R., and Higgins, C. W.: A simple model for the afternoon and early decay of convective turbulence over different land surfaces, Bound.-Lay. Meteorol., 141, 301-324, 2011.

Nieuwstadt, F. T. M. and Brost, R. A.: The decay of convective turbulence, J. Atmos. Sci., 43, 532-546, 1986.

Pino, D., Jonker, H. J. J., Arellano, J. V. G., and Dosio, A.: Role of shear and the inversion strength during sunset turbulence over land: characteristic length scales, Bound.-Lay. Meteorol., 121, 537-556, doi:10.1007/s10546-006-9080-6, 2006.

Poulos, S. G., Blumen, W., Fritts, D. C., Lundquist, J. K., Sun, J., Burns, S. P., Nappo, C., Banta, R., Newsom, R., Cuxart, J., Terradellas, E., Balsley, B., and Jensen, M.: A comprehensive investigation of the stable nocturnal boundary layer, B. Am. Meteorol. Soc., 83, 555-581, 2002.

Rao, T. N., Rao, D. N., and Mohan, K.: Classification of tropical precipitating systems and associated Z-R relationships, J. Geophys. Res., 116, 17699-17711, 2001.

Rao, T. N., Kirankumar, N. V. P., Radhakrishna, B., Rao, D. N., and Nakamura, K.: Classification of tropical precipitating systems using wind profiler spectral moments part I: algorithm description and validation, J. Atmos. Ocean. Tech., 25, 884-897, doi:10.1175/2007JTECHA1031.1, 2008.

Rao, T. N., Radhakrishna, B., Nakamura, K., and Prabhakara Rao, N.: Differences in raindrop size distribution from southwest monsoon to northeast monsoon at Gadanki, Q. J. Roy. Meteorol. Soc., 135, 1630-1637, 2009.

Reddy, K. K., Kozu, T., Nakamura, K., Ohno, Y., Srinivasulu, P., Anandan, V. K., Jain, A. R., Rao, P. B., Rao, R. R., Vishwanathan, G., and Rao, D. N.: Lower atmospheric wind profiler at Gadanki, tropical India: Initial results, Meteorol. Z., 10, 457466, 2001.

Sandeep, A., Rao, T. N., Ramkiran, C. N., and Rao, S. V. B.: Differences in atmospheric boundary-layer characteristics between wet and dry episodes of the Indian summer monsoon, Bound.Lay. Meteorol., 153, 217-236, doi:10.1007/s10546-014-9945-z, 2014.

Sastre, M., Yague, C., Roman, C. C., Maqueda, G., Salamanca, F., and Viana, S.: Evening transitions of the atmospheric boundary layers: characterization case studies and WRF simulations, Adv. Sci. Res., 8, 39-44, 2012.

Sorbjan, Z.: A numerical study of daily transitions in the convective boundary layer, Bound.-Lay. Meteorol., 123, 365-383, doi:10.1007/s10546-006-9147-4, 2007.

Srinivasulu, P., Yasodha, P., Kamaraj, P., Jayaraman, A., Reddy, S. N., and Satyanarayana, S.: Simplified active array L-band radar for atmospheric wind profiling: initial results, J. Atmos. Ocean. Tech., 28, 1436-1447, doi:10.1175/JTECH-D-11-00011.1, 2011. 
Srinivasulu, P., Yasodha, P., Kamaraj, P., Rao, T. N., Jayaraman, A., Reddy, S. N., and Satyanarayana, S.: $1280-\mathrm{MHz}$ active array radar wind profiler for lower atmosphere: System description and data validation, J. Atmos. Ocean. Tech., 29, 1455-1470, doi:10.1175/JTECH-D-12-00030.1, 2012.

Stull, R. B.: The energetics of entrainment across a density interface, J. Atmos. Sci., 33, 1260-1267, 1976.
Sun, J. and Wang, Y.: Effect of the Entrainment Flux Ratio on the Relationship between Entrainment Rate and Convective Richardson Number, Bound.-Lay. Meteorol., 126, 237-247, doi:10.1007/s10546-007-9231-4, 2008.

Van de Wiel, B. J. H., Moene, A. F., Steenveld, G. J., Baas, P., Bosveld, F. C., and Holtslag, A. A. M.: A conceptual view on inertial oscillations and nocturnal low-level jets, J. Atmos. Sci., 67, 2679-2689, doi:10.1175/2010JAS3289.1, 2010. 